\title{
Microbiology of Cheddar cheese made with different fat contents using a Lactococcus lactis single-strain starter
}

\author{
J. R. Broadbent, ${ }^{* 1}$ C. Brighton, ${ }^{*}$ D. J. McMahon, ${ }^{*}$ N. Y. Farkye, † M. E. Johnson, $\ddagger$ and J. L. Steele§ \\ *Department of Nutrition, Dietetics, and Food Sciences, and Western Dairy Center, Utah State University, Logan 84322-8700 \\ †Dairy Products Technology Center, California Polytechnic State University, San Luis Obispo 93407 \\ $\ddagger$ Center for Dairy Research, and \\ §Department of Food Science, University of Wisconsin-Madison 53706
}

\begin{abstract}
Flavor development in low-fat Cheddar cheese is typified by delayed or muted evolution of desirable flavor and aroma, and a propensity to acquire undesirable meaty-brothy or burnt-brothy off-flavor notes early in ripening. The biochemical basis for these flavor deficiencies is unclear, but flavor production in bacterial-ripened cheese is known to rely on microorganisms and enzymes present in the cheese matrix. Lipid removal fundamentally alters cheese composition, which can modify the cheese microenvironment in ways that may affect growth and enzymatic activity of starter or nonstarter lactic acid bacteria (NSLAB). Additionally, manufacture of low-fat cheeses often involves changes to processing protocols that may substantially alter cheese redox potential, salt-in-moisture content, acid content, water activity, or $\mathrm{pH}$. However, the consequences of these changes on microbial ecology and metabolism remain obscure. The objective of this study was to investigate the influence of fat content on population dynamics of starter bacteria and NSLAB over 9 mo of aging. Duplicate vats of full fat, $50 \%$ reduced-fat, and low-fat (containing $<6 \%$ fat) Cheddar cheeses were manufactured at 3 different locations with a single-strain Lactococcus lactis starter culture using standardized procedures. Cheeses were ripened at $8^{\circ} \mathrm{C}$ and sampled periodically for microbiological attributes. Microbiological counts indicated that initial populations of nonstarter bacteria were much lower in full-fat compared with low-fat cheeses made at all 3 sites, and starter viability also declined at a more rapid rate during ripening in full-fat compared with $50 \%$ reduced-fat and low-fat cheeses. Denaturing gradient gel electrophoresis of cheese bacteria showed that the NSLAB fraction of all cheeses was dominated by Lactobacillus curvatus, but a few other species of bacteria were sporadically detected. Thus, changes in fat level
\end{abstract}

Received December 1, 2012.

Accepted April 8, 2013.

${ }^{1}$ Corresponding author: jeff.broadbent@usu.edu were correlated with populations of different bacteria, but did not appear to alter the predominant types of bacteria in the cheese.

Key words: Cheddar cheese, low-fat cheese, flavor development, Lactococcus lactis

\section{INTRODUCTION}

Flavor development in Cheddar cheese is a complex and dynamic process whose intricacies are scripted by milk composition, the cultures and enzymes either present or added to make the cheese, and nuances in the manufacturing and ripening conditions used by different processors. Similar to many other internally bacterial ripened cheeses, Cheddar must be stored at low temperature $\left(5-13^{\circ} \mathrm{C}\right)$ for months and sometimes years to attain desired flavor and body attributes. During this period, microorganisms and enzymes trapped in the cheese matrix act on curd substrates in a manner that is heavily dictated by the curd microenvironment (e.g., cheese $\mathrm{pH}$, water activity, salt content, redox potential, and temperature), producing a heterogeneous mixture of volatile and nonvolatile flavor and aroma compounds that eventually confer mature cheese flavor (Fox et al., 1993; Fox and Wallace, 1997; Marilley and Casey, 2004; Smit et al., 2005; Ardö, 2006).

The most important microorganisms in the manufacture of Cheddar and related bacterial-ripened varieties are lactic acid bacteria (LAB), a diverse group of gram-positive, acid-tolerant, and strictly fermentative eubacteria that produce lactic acid as the major metabolic end product of carbohydrate metabolism. Types of LAB that occur in internally bacterial-ripened cheeses include deliberately added strains (e.g., starters and adjunct cultures) and adventitious species (primarily nonstarter LAB, or NSLAB) that enter cheese through milk or processing equipment (Peterson and Marshall, 1990). In Cheddar cheese, numbers of Lactococcus lactis starter bacteria frequently exceed $10^{9} \mathrm{cfu} / \mathrm{g}$ when ripening begins, but as maturation proceeds, the harsh cheese-ripening environment [little or no residual lactose, $\mathrm{pH} 5.0$ to $5.3,4-6 \%$ salt-in-moisture $(\mathbf{S} / \mathbf{M})$, 
and $\left.5-13^{\circ} \mathrm{C}\right]$ gradually diminish starter viability. A fraction of the dying starter cells undergo autolysis, which releases intracellular enzymes and cellular components (e.g., sugars and nucleic acids) into the cheese matrix (Fryer, 1969). At the same time, NSLAB (whose initial numbers are commonly below $10^{2} \mathrm{cfu} / \mathrm{g}$ in cheese made under good sanitary conditions with high-quality pasteurized milk) begin to grow and eventually plateau at cell densities of $10^{7}$ to $10^{8} \mathrm{cfu} / \mathrm{g}$ after 3 to 9 mo of aging (Peterson and Marshall, 1990). Nonstarter LAB populations can be quite diverse, but are usually dominated by facultatively heterofermentative species of lactobacilli (Broome et al., 1990; Fitzsimons et al., 1999; Beresford et al., 2001; Crow et al., 2001; Swearingen et al., 2001; Broadbent et al., 2003).

Given the causal role of LAB in cheese flavor development, research to define the biochemical basis for flavor changes in cheese has logically focused on the microbiology and physiology of species present in cheese (for reviews, see Beresford et al., 2001; Marilley and Casey, 2004; Smit et al., 2005; Ardö, 2006; Broadbent and Steele, 2007; Cogan et al., 2007; Drake, 2007). Those efforts have identified several important biochemical and chemical processes that occur during maturation, and demonstrated that starters, adjuncts, and NSLAB can have an intimate role in those processes. This knowledge has served industry efforts to promote flavor development in many traditional cheese varieties, but efforts to extend it to low-fat Cheddar (LFC) cheese has proven to be difficult. As a result, LFC varieties continue to suffer from low intensity of desirable flavor such as buttery, creamy, or caramel, and commonly develop pronounced meaty-brothy or burnt-brothy offflavors (Milo and Reineccius, 1997; Fenelon et al., 2000; Drake et al., 2010).

Efforts to understand the influence of fat reduction on flavor development are challenged by the fact that lipid removal fundamentally alters cheese composition, which in turn modifies the cheese microenvironment in such a manner that bacterial growth and enzymatic activity - the factors primarily responsible for flavor - are also altered (Mistry 1995). For example, the moisture content of LFC cheese is usually increased to 52 to $55 \%$ to reduce excessive firmness, but this modification gives a lower $\mathrm{S} / \mathrm{M}$ content than what is typically found in a full-fat Cheddar cheese. Increasing the S/M content of reduced-fat cheeses to a similar level as higher-fat cheeses may result in a reduced-fat cheese that is excessively salty. A decreased S/M content may promote bacterial survival and metabolism in the curd during aging (Mistry 1995; Nauth and Ruffie, 1995). Furthermore, manufacture of cheese with lower fat content often involves other changes to processing protocols that may alter cheese redox potential, acid content, water activity, or $\mathrm{pH}$. Unfortunately, the consequences of changes in the cheese microenvironment on Cheddar cheese microbiology and metabolism remain poorly defined.

Given the central role of microorganisms in cheese flavor development, it has been our hypothesis that flavor deficiencies in low-fat cheese are likely a result of 3 scenarios: first, microbial growth and metabolism (and, therefore, end product formation) might be similar in full- and low-fat cheeses, but sensory perception of those metabolites is somehow altered by differences in the physicochemical environment (e.g., fat, moisture, or S/M contents). Alternatively, changes to the cheese chemical environment may alter the population dynamics and composition of microbial populations in cheese, which in turn changes the balance of flavor compounds produced in the cheese. Finally, culture physiology itself (and, thus, overall metabolism and end product formation) might be altered by differences in the physicochemical environment in ways that retard production of desirable flavor- and aroma-active metabolites, and enhance production of undesirable flavor- and aromaactive metabolites. These scenarios are not, of course, mutually exclusive. To explore our hypothesis, we investigated the consequences of fat removal in Cheddar cheese on population dynamics of starter and NSLAB over a 9-mo aging period. This study was part of a larger multi-institutional effort to explore the effect of fat reduction on texture (Rogers et al., 2009), flavor (Drake et al., 2010), and microbiology of Cheddar cheese made by the same procedure at 3 different locations.

\section{MATERIALS AND METHODS}

\section{Cheddar Cheese Production}

Cheddar cheese was manufactured at 3 fat levels as defined by the US Code of Federal Regulations to represent full-fat Cheddar (FFC; 21 CFR 133.113.a.1), $50 \%$ reduced-fat Cheddar (RFC; 21 CFR 101.62.e), and LFC cheese (21 CFR 101.62.b.2). All cheeses were made using a stirred curd protocol rather than cheddaring.

Four different cheeses were made in duplicate and in randomized order using Lc. lactis ssp. lactis M70 (DuPont Danisco USA Inc., Madison, WI) as a singlestrain starter culture following the procedures described by Rogers et al. (2009). Experimental cheeses included 2 FFC cheeses (FFC1 and FFC2) that only differed by the inclusion of a curd wash step in FFC2, RFC, and LFC. All 4 cheeses were made in duplicate at California Polytechnic State University (CPSU; San Luis Obispo) and at Utah State University (USU; Logan). Cheeses FFC1, FFC2, and LFC were made in duplicate 
at the University of Wisconsin-Madison (UW). After manufacture, the cheeses were vacuum packaged and ripened at $8^{\circ} \mathrm{C}$. Proximate analysis was performed as described by Rogers et al. (2009), except that the $\mathrm{pH}$ of cheeses made at UW was measured using the quinhydrone method (Van Slyke and Price, 1979).

\section{Microbiological Sampling}

At 2 and $6 \mathrm{wk}$, and at mo 3,6, and 9, cheese samples $(11 \mathrm{~g})$ were collected from the interior of each cheese and briefly stored $(<1 \mathrm{wk}$ to accommodate logistics of working across different manufacturing sites) at $4^{\circ} \mathrm{C}$ before plating. The samples were homogenized in $99 \mathrm{~mL}$ of sterilized $2 \%$ sodium citrate (warmed to $45^{\circ} \mathrm{C}$ ) using a Stomacher 400 Circulator laboratory blender (Seward Laboratory Systems Inc., Bohemia, NY) set for $2 \mathrm{~min}$ at $230 \mathrm{rpm}$. Serial dilutions were prepared in $0.1 \%$ peptone water, and then total bacterial counts (cfu/g of cheese) were enumerated by the pour plate method with Elliker agar, which was incubated anaerobically for $2 \mathrm{~d}$ at $30^{\circ} \mathrm{C}$. At the same time, samples were also plated on Rogosa SL agar for enumeration of NSLAB, and those plates were also incubated anaerobically for $2 \mathrm{~d}$ at $30^{\circ} \mathrm{C}$ before enumeration. Starter numbers were determined by subtracting the NSLAB count on Rogosa SL from the total bacterial count.

\section{Denaturing Gradient Gel Electrophoresis}

As cheese samples were collected for microbiological sampling; 6 additional samples were plated in duplicate on de Man, Rogosa, and Sharpe (MRS) agar to propagate cells for analysis by denaturing gradient gel electrophoresis (DGGE). Cells for DGGE were prepared by spread plating $0.1-\mathrm{mL}$ samples of the $10^{-1}$ dilution on MRS agar with aerobic or anaerobic incubation at 30 or $45^{\circ} \mathrm{C}$ for $48 \mathrm{~h}$, or $10^{\circ} \mathrm{C}$ for 1 wk. These different incubation conditions were used to foster growth and detection of bacteria that might be present in low numbers in the cheese. After incubation, $500 \mu \mathrm{L}$ of DNase/RNase-free water (VWR International LLC, West Chester, PA) was added to each plate and the cells were scraped from the agar and pooled using a glass plate spreader, and then transferred into a $1.5-\mathrm{mL}$ microcentrifuge tube. The cells were pelleted by centrifugation at $16,000 \times g$ for $1 \mathrm{~min}$; then the supernatant was discarded and the pellet-containing tubes placed at $-80^{\circ} \mathrm{C}$.

Total genomic DNA was isolated from the cell pellets and directly from cheese samples $(250 \mathrm{mg})$ using the PowerSoil DNA isolation kit (MO BIO Laboratories Inc., Carlsbad, CA) as directed by the kit supplier. The variable V3 region of the bacterial 16S rRNA gene was amplified from template DNA isolated from cells or cheese by PCR with forward (5'-GCCCGCCGCGCGCGGCGGGCGGGGCGGGGGCACGGGGGGCCTACGGGAGGCAGCAG-3') and reverse (5'-ATTACCGCGGCTGCTGG-3') primers designed to bind highly conserved regions of the gene (the resulting amplicon corresponds to nucleotide positions 341 to 534 in the 16S rRNA gene of Escherichia coli; Clarridge 2004). The forward primer contained a GC-rich sequence (GC clamp; underlined) to help stabilize the melting characteristics (Muyzer, et al., 1993).

To create a positive control for PCR and DGGE, template DNA was extracted from pure cultures of $L c$. lactis ssp. lactis M70, Lactobacillus casei ATCC 334, Lactobacillus plantarum CB1, Lactobacillus helveticus CNRZ32, Streptococcus thermophilus ATCC 19987, and E. coli ATCC 4700, which were obtained from our laboratory collection.

The PCR was performed with a DNA Thermal Cycler (model 480; PerkinElmer, Wellesley, MA) in a final volume of $50 \mu \mathrm{L}$ that contained $1 \times$ TaqMaster PCR Enhancer (5 Prime Inc., Gaithersburg, MD), 1× Buffer B (Fisher Scientific, Pittsburgh, PA), $2.5 \mathrm{mM} \mathrm{MgCl} 2,25$ $\mu M$ concentration of each deoxyribonucleotide triphosphate (dNTP), 2.5 IU of Taq DNA polymerase (Fisher Scientific), $1 \mu M$ concentration of each primer, and 1 $\mu \mathrm{L}$ of template DNA solution. The PCR reaction was overlaid with $50 \mu \mathrm{L}$ of mineral oil (PerkinElmer). To minimize spurious priming, touchdown PCR was used (Don et al. 1991), wherein the annealing temperature of the first PCR cycle was $10^{\circ} \mathrm{C}$ higher $\left(65^{\circ} \mathrm{C}\right)$ than the optimum anneal temperature, and every second cycle, the anneal temperature was decreased $1^{\circ} \mathrm{C}$ until it reached the optimum annealing temperature, whereupon 15 additional cycles were completed. The presence of amplicon was verified by electrophoresis in $1 \%$ (wt/vol) agarose gels and ethidium bromide staining.

Denaturing gradient gel electrophoresis was performed with the CBS Scientific Co. (Solana Beach, CA) DGGE system. Gels were made with $8 \%$ (wt/vol) acrylamide (acrylamide-N,N-methylene-bisacrylamide; 27:1; VWR International LLC) in $1 \times$ TAE buffer [40 $\mathrm{m} M$ Tris acetate (pH 7.4), $20 \mathrm{~m} M$ sodium acetate, and $1 \mathrm{mM} \mathrm{Na} \mathrm{Na}_{2}$-EDTA] with a gradient of 25 to $60 \%$ denaturant $[100 \%$ denaturant is $7 M$ urea and $40 \%$ (wt/vol) deionized formamide]. Ten microliters of PCR product was combined with $5 \mu \mathrm{L}$ of $6 \times$ loading buffer $[0.25 \%$ bromophenol blue, $0.25 \%$ xylene cyanol, and $40 \%$ (wt/ vol) sucrose in double-distilled $\mathrm{H}_{2} \mathrm{O}$ ], and loaded on the polyacrylamide gel. The DGGE was performed at $60^{\circ} \mathrm{C}$ and $150 \mathrm{~V}$ for $30 \mathrm{~min}$, and then for an additional $5 \mathrm{~h}$ at $200 \mathrm{~V}$ at the same temperature. Gels were stained by spreading $20 \mathrm{~mL}$ of SYBR gold solution (Molecular Probes Inc., Carlsbad, CA) diluted 1/10,000 over the 
surface of the gel. The gel was incubated in the dark for 10 min, washed repeatedly with double-distilled $\mathrm{H}_{2} \mathrm{O}$, and then photographed using a UV transilluminator (UVP LLC, Upland, CA). Bands that were prominent, unique to the sample, or changed in intensity (i.e., appeared or disappeared as a function of sampling date), were excised with a clean razor blade and placed in 1.5-mL microcentrifuge tubes for further analysis.

\section{Cloning and Sequencing of $16 \mathrm{~S}$ Ribosomal DNA Fragments}

Deoxyribonucleic acid was eluted from denaturing gradient gels using the procedure developed by Etokebe and Spurkland (2000) and amplified once more by PCR with the same primers and reaction conditions used to prepare the original amplicons. After PCR, newly formed amplicons were purified using the MinElute PCR Purification Kit (Qiagen Inc., Valencia, CA) and then cloned into E. coli $10 \mathrm{G}$ using the pSMART GC HK Cloning Kit (Lucigen Corp., Middleton, WI). Five kanamycin-resistant colony-forming units from each cloning reaction were streaked for purity and then single-colony isolates were inoculated into $10 \mathrm{~mL}$ of LuriaBertani (LB) broth and grown overnight at $37^{\circ} \mathrm{C}$ with mild shaking. Plasmid DNA was isolated from these cells by the alkaline lysis method, and the presence of the plasmid was confirmed by electrophoresis in $1 \%$ (wt/vol) agarose gels with ethidium bromide staining (Sambrook et al., 1989).

Plasmid DNA samples were purified by extracting (1:1) with phenol:chloroform:isoamyl alcohol (25:24:1) and then sent to the Center for Integrated BioSystems at USU for bidirectional sequencing by fluorescent dideoxy chain termination chemistry. Nucleotide sequence similarity searches were performed using BLAST tools available through the National Institutes of Health Center for Biotechnology Information (http://www. ncbi.nlm.nih.gov) to determine the bacterial species from which each amplicon was most likely derived.

\section{RESULTS AND DISCUSSION}

\section{Microbiological Counts}

Proximate analysis of the cheeses made at each location confirmed that the targeted fat reductions were achieved for RFC and LFC cheeses, and that the 2 full-fat cheeses (FFC1 and FFC2) were similar in composition (Table 1). Not surprisingly, some minor but statistically significant differences in composition were also detected between cheeses of the same type made at different locations (Table 1 ). The more pronounced and expected differences in moisture and protein content between cheeses with different fat levels were previously shown to influence the rheological and sensory properties of these cheeses (Rogers et al., 2009; Drake et al., 2010), and would effect greater changes to the cheese microenvironment that, in turn, could influence the microbial ecology of ripening curd (Broadbent et al., 2002).

Enumeration of starter and NSLAB in experimental cheeses showed that all samples contained approximately $1 \times 10^{9}$ starter cfu/g 2 to 6 wk after manufacture (Table 2). After $3 \mathrm{mo}$, starter numbers were still greater than $1 \times 10^{8} \mathrm{cfu} / \mathrm{g}$ in $50 \% \mathrm{RFC}$ and LFC cheeses made

Table 1. Mean composition ( \pm SEM) of experimental Cheddar cheeses made in California [California Polytechnic State University (CPSU), San Luis Obispo], Utah [Utah State University (USU), Logan] or Wisconsin [University of Wisconsin-Madison (UW)]

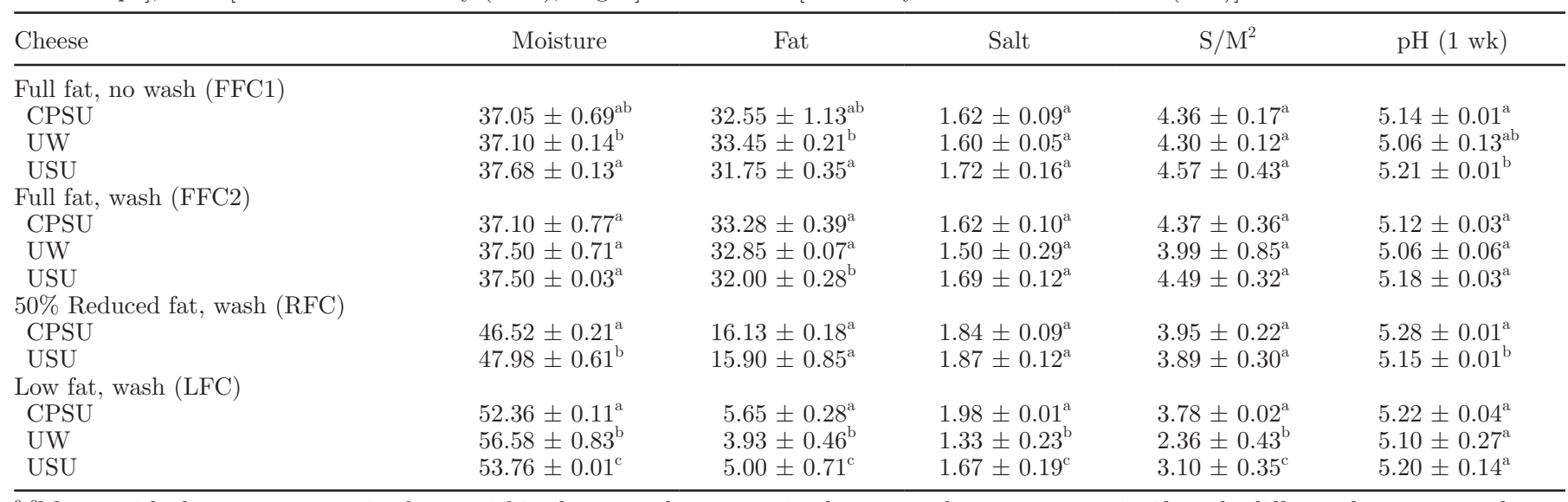

\footnotetext{
${ }^{\mathrm{a}-\mathrm{c}}$ Means with the same superscript letter within the same cheese type in the same column were not significantly different from one another at a $95 \%$ confidence interval.

${ }^{1}$ All values except $\mathrm{pH}$ represent a percentage.

${ }^{2}$ Salt-in-moisture.
} 
at each site, but had declined by about 1 more order of magnitude in the no-wash FFC1 and washed FFC2 varieties made at each location. Similar differences in the degree to which starter viability declined in RFC and LFC versus both FFC cheeses were also noted in 6-mo-old samples (Table 2). By 9 mo, starter numbers in most experimental cheeses could not be quantified because they had fallen to levels below those of the NSLAB population.

Differences were also noted in levels of NSLAB in FFC varieties versus RFC and LFC cheeses. As is shown in Table 2, NSLAB populations in FFC1 or FFC2 cheeses rarely exceeded $1 \times 10^{3} \mathrm{cfu} / \mathrm{g}$ within 2 wk of pressing, but were rarely below $1 \times 10^{5} \mathrm{cfu} / \mathrm{g}$ in corresponding RFC and LFC cheeses. Moreover, NSLAB levels exceeded $1 \times 10^{7} \mathrm{cfu} / \mathrm{g}$ in all LFC samples by 6 wk of ripening, whereas only a few FFC1 or FFC2 cheeses contained more than $1 \times 10^{6} \mathrm{NSLAB} \mathrm{cfu} / \mathrm{g}$ after even 6 to 9 mo of aging (Table 2). The NSLAB populations in RFC cheese during ripening were essentially intermediate to those of their FFC and LFC experimental counterparts. Overall, these results are consistent with the findings of Nauth and Ruffie (1995), who noted high numbers of NSLAB in young $50 \%$ RFC cheese and persistence of starter populations during aging.

\section{Microbial Diversity of Cheeses with Different Fat Contents}

The relationship between microbial population dynamics and cheese flavor development is a function of both the numbers and types of bacteria present in the ripening cheese matrix. The dairy industry has an interest in the manufacture of high-quality cheese with reduced fat content, but the consequences of fat reduction on cheese microenvironment and microbiology remain obscure. To explore this question, we examined the microbiological diversity during ripening in Cheddar cheeses with different fat contents manufactured at 3 locations. Unfortunately, DGGE and nucleotide sequence analysis of DNA isolated directly from cheese was exclusively derived from the starter bacterium $L c$. lactis. We attribute this result to the fact that DNA in cheese may come from live or dead bacteria, and the overwhelming number of starter bacteria in the system. In contrast, DGGE analysis of PCR products generated with universal primers from cheese extracts provided considerable insight into the microbial diversity of culturable bacteria in each cheese. For example, DGGE fingerprints from extracts incubated at $10^{\circ} \mathrm{C}$ were very similar, albeit not identical, across all 4 cheeses made at USU (Figure 1). Similar results were noted for extracts plated at $30^{\circ} \mathrm{C}$ (data not shown). Cloning and DNA sequence analysis of the most dominant bands in each gel

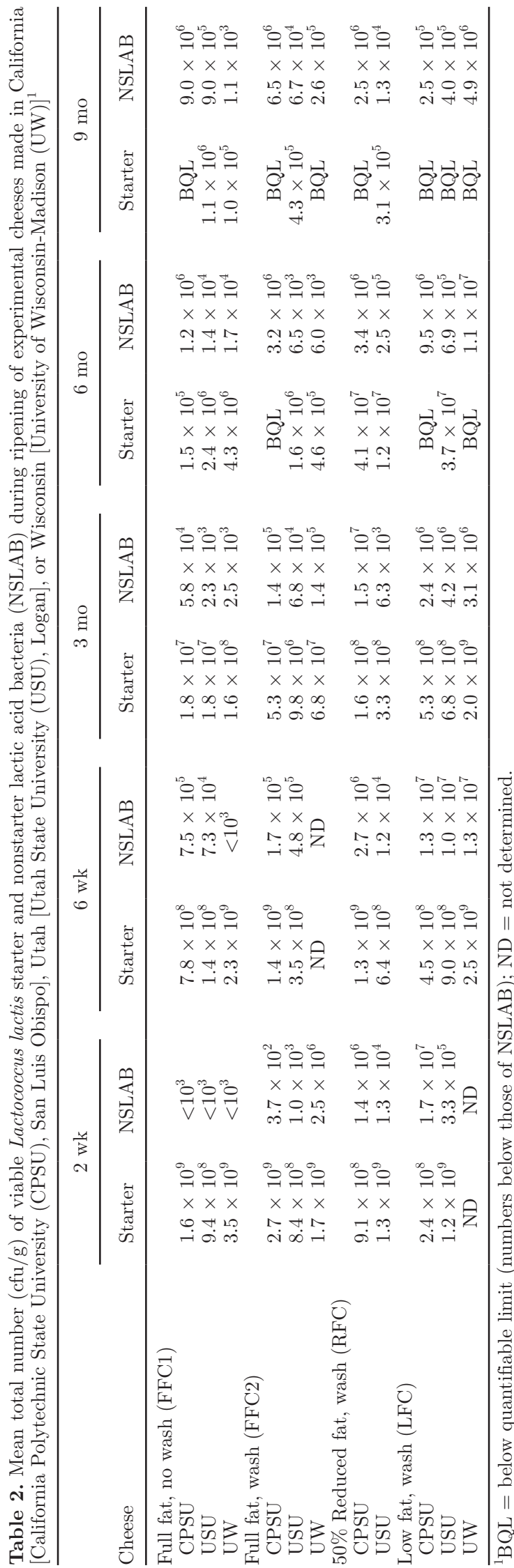

Journal of Dairy Science Vol. 96 No. 7, 2013 
revealed that Lactobacillus curvatus (band 8) was the predominant NSLAB species in all cheeses, and showed that the starter Lc. lactis (band 7) was still present in most samples even after 9 mo of ripening (Table 3 ). As is shown in Figure 2 and Table 3, Lb. curvatus (band 8) was also the predominant NSLAB species in cheeses made at CPSU or UW. However, Lactobacillus coryniformis (Figure 2, band 9) was intermittently detected in FFC or LFC cheeses from all 3 manufacturing facilities. Additionally, Lactobacillus casei was detected in 6- and 9-mo-old FFC2 cheese made at CPSU, and Lactobacillus helveticus was detected in 3-mo-old cheese made at USU (Table 3). None of these bacteria was deliberately added to our experimental cheeses.

Correlation of starter and NSLAB counts with DGGE results at $10^{\circ} \mathrm{C}$ for Lc. lactis and Lb. curvatus suggests

\section{FFC1}

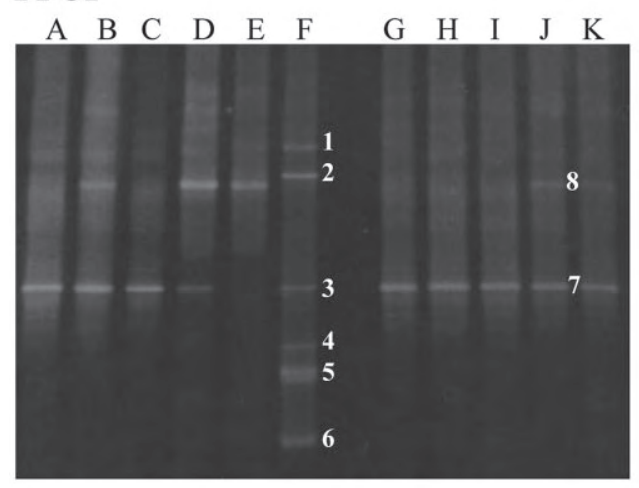

RFC

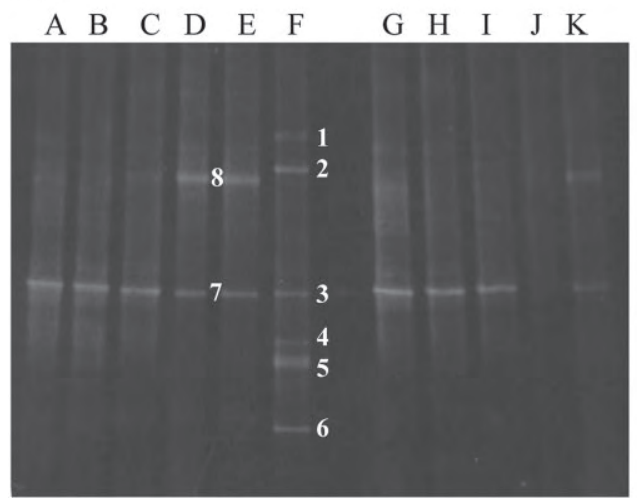

that these species could be detected by DGGE when populations in cheese were greater than $10^{5} \mathrm{cfu} / \mathrm{g}$. This observation is in reasonable agreement with the findings of Cocolin and coworkers (2004), who reported that DGGE had a detection limit of $10^{4} \mathrm{cfu} / \mathrm{mL}$ in cheese extracts. Denaturing gradient gel electrophoresis is not a quantitative tool, however, and the methodology used in this study would introduce additional bias between the actual levels of a particular species in cheese and its prevalence after enrichment on a rich, nonselective agar (MRS). Nonetheless, it is reasonable to believe that results from $10^{\circ} \mathrm{C}$ incubations would capture those species that are able to grow or persist in cheese ripened at $8^{\circ} \mathrm{C}$. Additionally, enrichment on nonselective agar also affords an opportunity for outgrowth of bacterial spores, and incubations at 30 or $45^{\circ} \mathrm{C}$ were expected to capture

\section{FFC2}

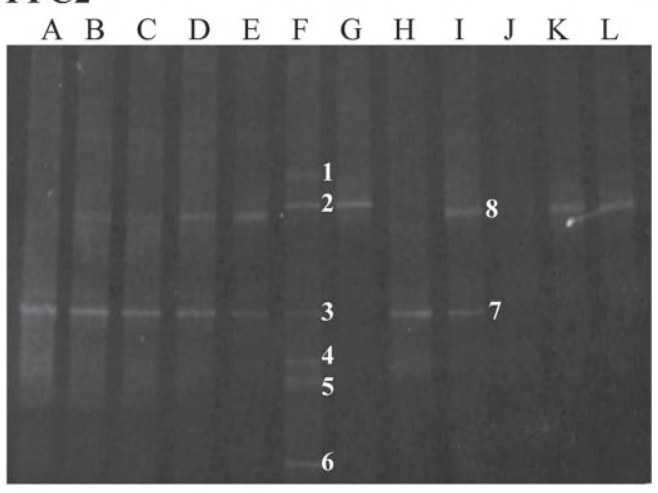

LFC

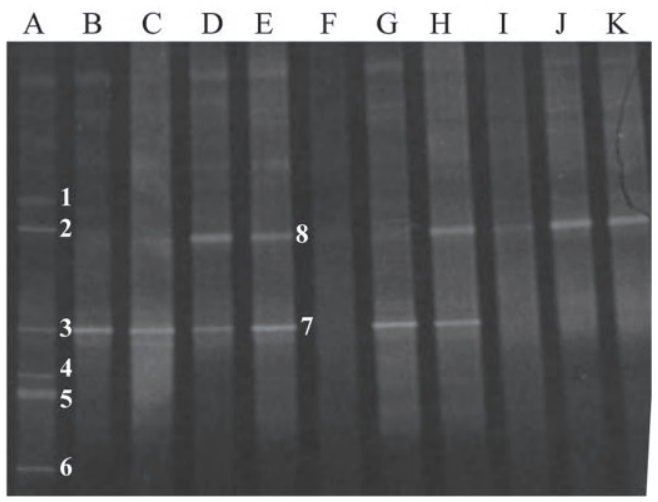

Figure 1. Denaturing gradient gel electrophoresis (DGGE) profile of $16 \mathrm{~S}$ ribosomal DNA (rDNA) PCR products recovered from regular full-fat Cheddar (FFC1), washed full-fat Cheddar (FFC2), reduced-fat Cheddar (RFC), or low-fat Cheddar (LFC) cheeses made at Utah State University (Logan) after incubation of cheese extracts on de Man, Rogosa, and Sharpe (MRS) agar at 10 ${ }^{\circ} \mathrm{C}$. Panel FFC1: lanes correspond to replicate samples of 2-wk-old (A and G), 6-wk-old (B and H), 3-mo-old (C and I), 6-mo-old (D and J), and 9-mo-old cheeses (E and K). Lane F displays products from the DGGE-positive control and standard, which included bands 1 (Lactobacillus plantarum), 2 (Lactobacillus helveticus), 3 (Lactococcus lactis ssp. lactis M70; starter culture), 4 (Streptococcus thermophilus), 5 (Escherichia coli), and 6 (Lactobacillus casei). Nucleotide sequence analysis of bands 7 and 8 indicated that they were derived from Lc. lactis and Lactobacillus curvatus, respectively. Panel FFC2: replicate samples of 2-wk-old (lanes A and H), 6-wk-old (B and I), 3-mo-old (C and J), 6-mo-old (D and K), and 9-mo-old cheeses (E and L). Lane F shows the positive control and standard. Lane G shows a Lactobacillus helveticus-positive control. Panel RFC: replicate samples of 2-wk-old (lanes $\mathrm{A}$ and $\mathrm{G}$ ), 6-wk-old (B and $\mathrm{H}$ ), 3-mo-old (C and I), 6-mo-old (D and J), and 9-mo-old cheeses (E and $\mathrm{K}$ ). Lane $\mathrm{F}$ displays the positive control and standard. Panel LFC: lane A shows the positive control and standard. Other lanes correspond to replicate samples of 2-wk-old (B and $\mathrm{G}$ ), 6-wk-old (C and H), 3-mo-old (D and I), 6-mo-old (E and J), and 9-mo-old cheeses (F and $\mathrm{K}$ ). 
Table 3. Species detected by DNA sequence analysis of denaturing gradient gel electrophoresis (DGGE) fragments from extracts of experimental Cheddar cheeses made in California [California Polytechnic State University (CPSU), San Luis Obispo], Utah [Utah State University (USU), Logan], or Wisconsin [University of Wisconsin-Madison (UW)] ${ }^{1}$

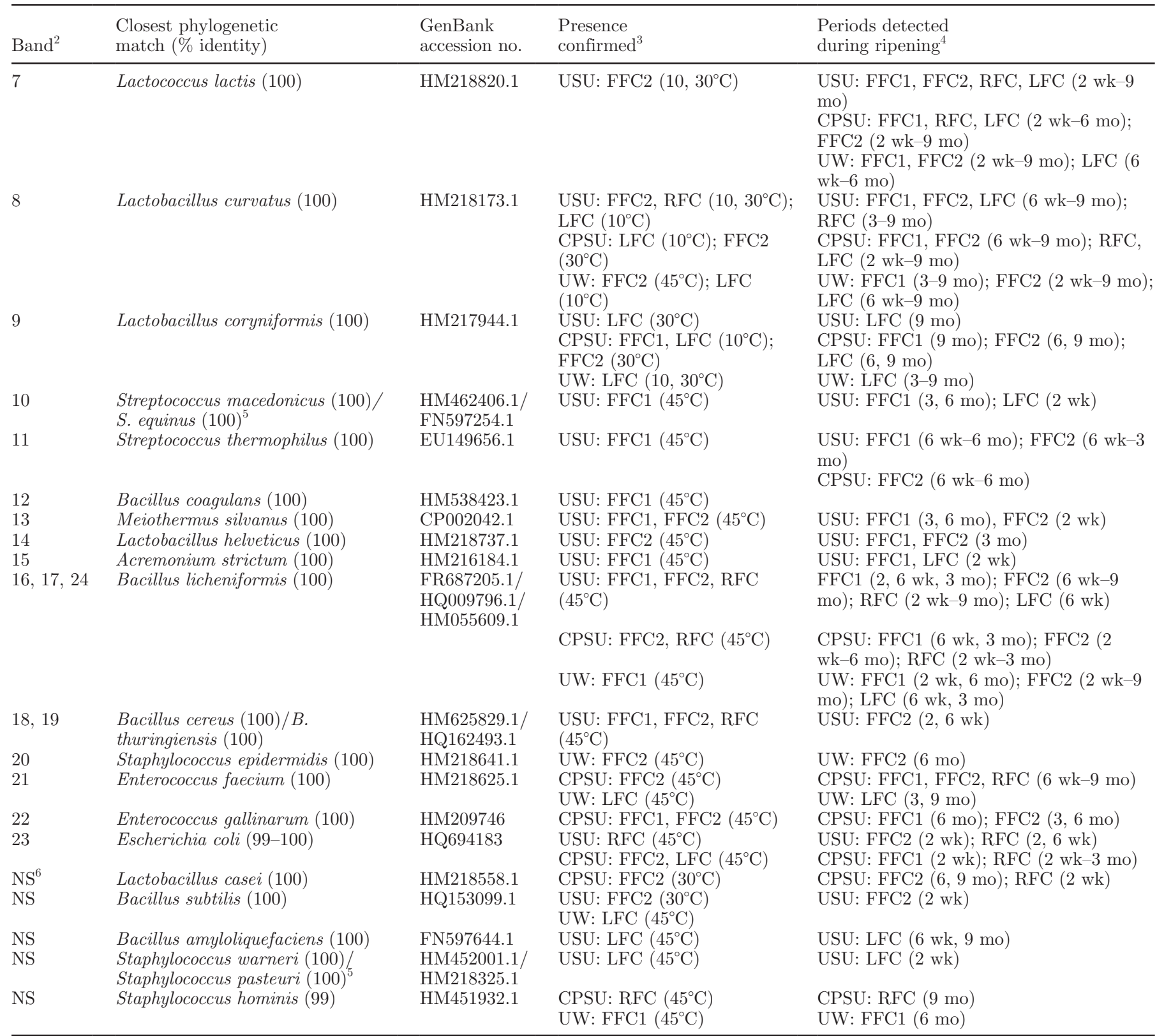

${ }^{1} \mathrm{FFC} 1$ = full-fat Cheddar; FFC2 = washed full-fat Cheddar; RFC $=$ reduced-fat Cheddar; LFC = low-fat Cheddar.

${ }^{2}$ Numbers correspond to fragments labeled in Figures 1 to 3.

${ }^{3}$ Fragment excised, cloned, and sequenced. Temperature indicates enrichment treatment from which the fragment was obtained.

${ }^{4}$ Fragment detected by DGGE in cheese samples after specified period of ripening. Identification based on fragment cloning or fragment location in DGGE gels relative to standards or cloned bands.

${ }^{5}$ Nucleotide sequence of fragment could not discriminate between the 2 species noted.

${ }^{6} \mathrm{NS}=$ not shown

species that either may not grow in cheese or are present at very low numbers in the matrix. As would therefore be expected, DGGE profiles from cheese extracts incubated on MRS agar at $45^{\circ} \mathrm{C}$ were considerably more diverse than those obtained for cheese extracts plated at 10 or $30^{\circ} \mathrm{C}$ (Figure 3). Cloning and DNA sequence analysis of DGGE fragments collected from these gels led to the detection of 19 additional microbes from 8 different genera, including several species of Streptococcus, Staphylococcus, Enterococcus, and Bacillus (Table 


\section{FFC1-CPSU}

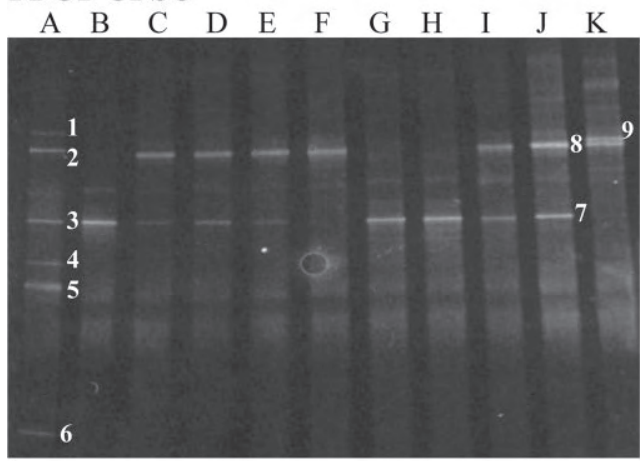

FFC1-UW

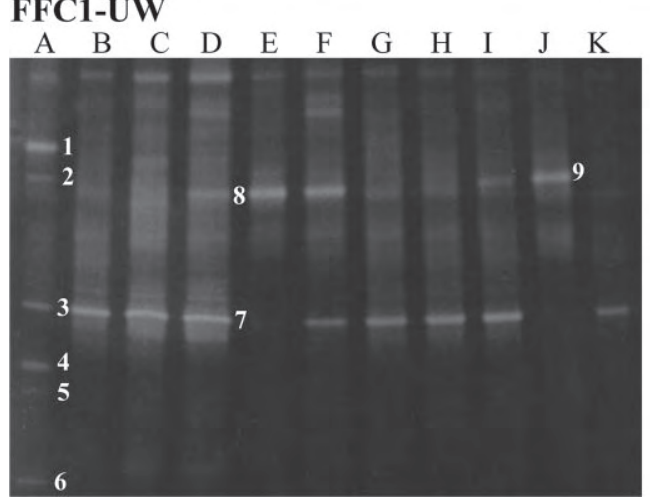

\section{LFC-CPSU}

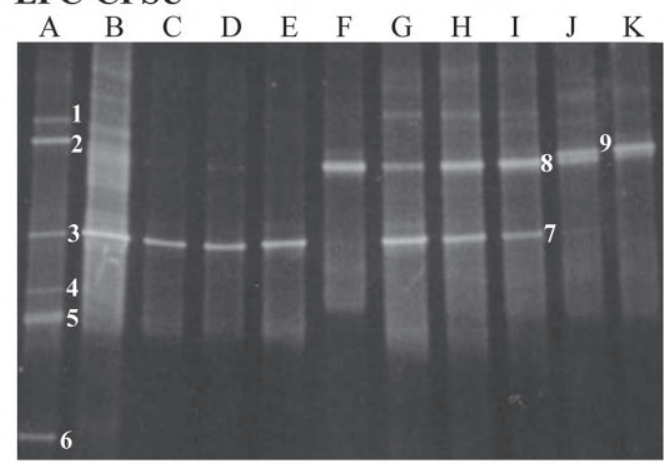

\section{LFC-UW}

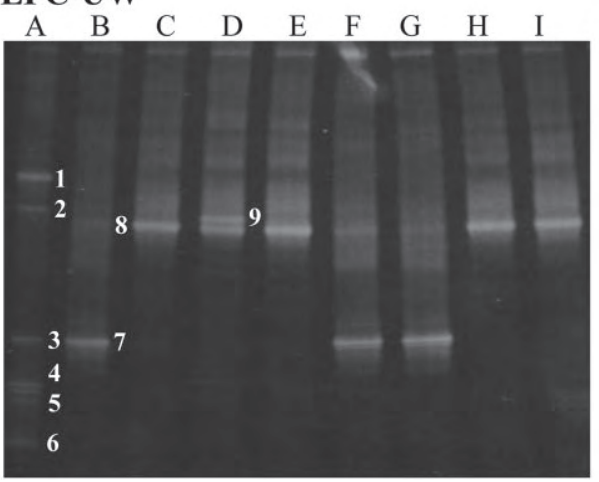

Figure 2. Denaturing gradient gel electrophoresis (DGGE) profile of $16 \mathrm{~S}$ ribosomal DNA (rDNA) PCR products recovered from regular full-fat Cheddar (FFC1) or low-fat Cheddar (LFC) cheeses made at California Polytechnic State University (CPSU; San Luis Obispo) or the University of Wisconsin-Madison (UW) after incubation of cheese extracts on de Man, Rogosa, and Sharpe (MRS) agar at $10^{\circ} \mathrm{C}$. Panel FFC1-CPSU: lane A displays products from the DGGE-positive control and standard, which included bands 1 (Lactobacillus plantarum), 2 (Lactobacillus helveticus), 3 (Lactococcus lactis ssp. lactis M70; starter culture), 4 (Streptococcus thermophilus), 5 (Escherichia coli), and 6 (Lactobacillus casei). Other lanes correspond to replicate samples of 2-wk-old (B and G), 6-wk-old (C and H), 3-mo-old (D and I), 6-mo-old ( $\mathrm{E}$ and $\mathrm{J}$ ), and 9-mo-old cheeses ( $\mathrm{F}$ and $\mathrm{K})$. Nucleotide sequence analysis of bands 7, 8, and 9 indicated that they were derived from Lc. lactis, Lactobacillus curvatus, and Lactobacillus coryniformis, respectively. Panel LFC-CPSU: lane A shows the positive control and standard. Other lanes correspond to replicate samples of 2-wk-old (B and G), 6-wk-old (C and H), 3-mo-old (D and I), 6-mo-old (E and J), and 9-mo-old cheeses (F and K). Panel FFC1-UW: lane A shows the positive control and standard. Other lanes correspond to replicate samples of 2-wk-old (B and $\mathrm{G}), 6$-wk-old (C and $\mathrm{H}$ ), 3-mo-old (D and I), 6-mo-old (E and J), and 9-mo-old cheeses (F and $\mathrm{K}$ ). Panel LFC-UW: lane A shows the positive control and standard. Other lanes correspond to replicate samples of 6-wk-old (B and F), 3-mo-old (C and G), 6-mo-old (D and H), and 9-moold cheeses (E and I).

3). Adventitious Streptococcus thermophilus (Figure 3, band 11), for example, was detected over time in FFC1 and FFC2 cheeses made at USU, and in FFC2 cheese from CPSU (Table 3). Additionally, DGGE fragments corresponding to the $16 \mathrm{~S}$ rRNA gene of a bacterium related to Streptococcus macedonicus and Streptococcus equinus (Figure 3, band 10) were observed in FFC1 made at USU and FFC2 made at CPSU after 3 to 6 mo of aging (Table 3). The origin of these bacteria is unknown, but neither is able to grow at the ripening temperature of $8^{\circ} \mathrm{C}$ (Hardie, 1986).

Some species of staphylococci are associated with smear-ripened cheese (Beresford et al., 2001), and 3 species were recovered from various cheeses made in this study: Staphylococcus epidermidis, Staphylococcus hominis, and a bacterium most closely related to Staph- ylococcus warneri and Staphylococcus pasteuri (Table 3). All 3 are commensal species associated with human skin (Kloos and Schleifer, 1986), so their presence may be due to cross-contamination during cheese processing or sample handling. More importantly, none of these bacteria is able to grow at $8^{\circ} \mathrm{C}$ (Kloos and Schleifer, 1986), so their actual numbers in cheese samples were likely very low.

In contrast, enterococci such as Enterococcus faecium (Figure 3, band 21) and Enterococcus gallinarum (Figure 3 , band 22) do grow at $10^{\circ} \mathrm{C}$ (Hardie, 1986) and are thought to contribute to flavor development (Ogier and Serror, 2008). In the current study, Enterococcus faecium was recovered from CPSU cheeses FFC1, FFC2, and RFC throughout ripening, as well as in LFC made at UW after 3 and 6 mo (Table 3). Enterococcus gal- 

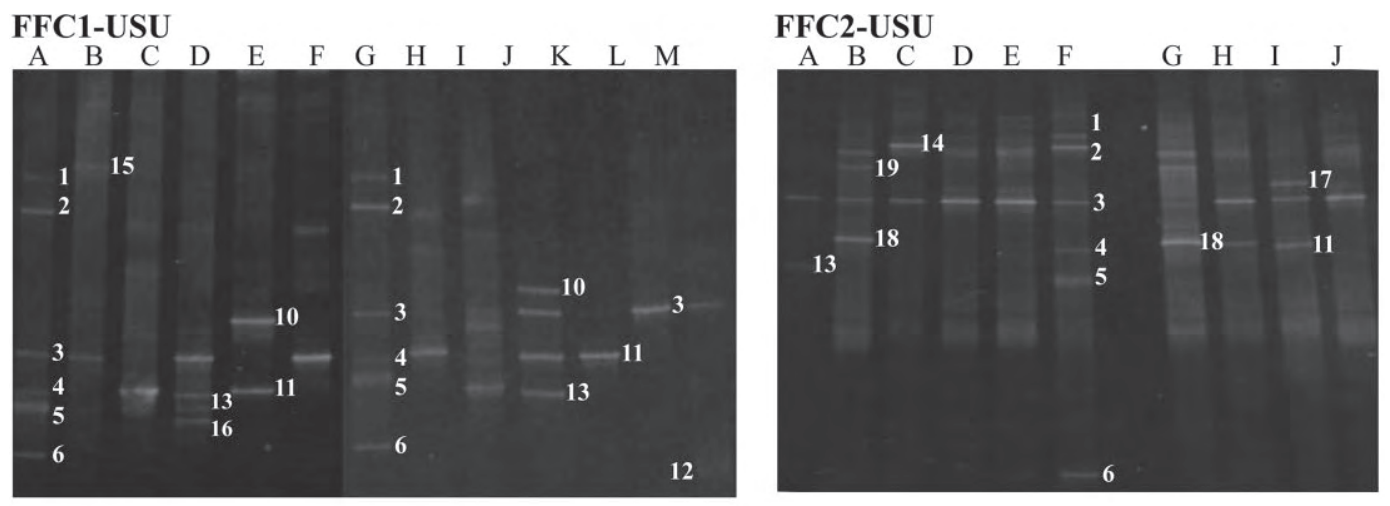

\section{FFC2-UW}

A $\quad$ B $\quad$ C $\quad$ D $\quad$ E

F $\quad$ G $\quad H \quad$ I

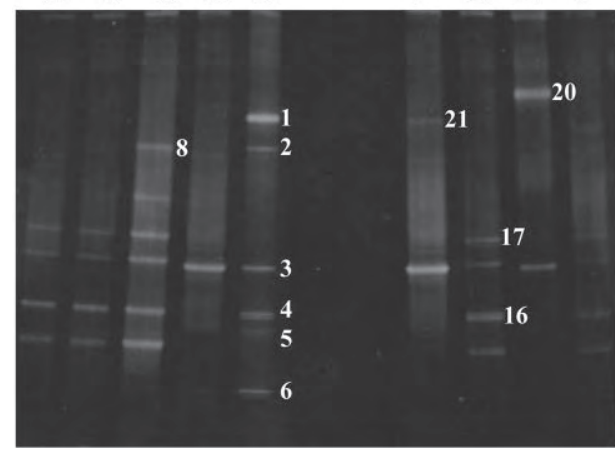

FFC2-CPSU

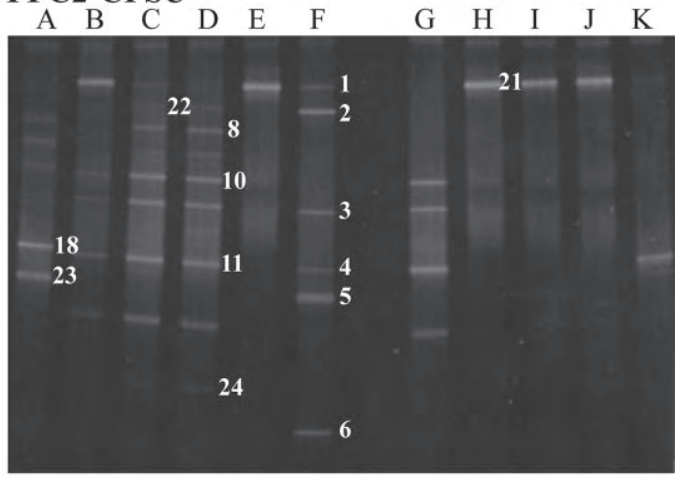

Figure 3. Denaturing gradient gel electrophoresis (DGGE) profile of $16 \mathrm{~S}$ ribosomal DNA (rDNA) PCR products recovered from regular full-fat Cheddar (FFC1 and FFC2) cheeses made at Utah State University (USU; Logan), California Polytechnic State University (CPSU; San Luis Obispo), or the University of Wisconsin-Madison (UW) after incubation of cheese extracts on de Man, Rogosa, and Sharpe (MRS) agar at $45^{\circ} \mathrm{C}$. Panel FFC1-USU: lanes A and G shows the DGGE-positive control and standard, which included bands 1 (Lactobacillus plantarum), 2 (Lactobacillus helveticus), 3 (Lactococcus lactis ssp. lactis M70; starter culture, which is also present in lane L), 4 (Streptococcus thermophilus), 5 (Escherichia coli), and 6 (Lactobacillus casei). Other lanes correspond to replicate samples of 2-wk-old (B and H), 6-wk-old (C and I), 3-mo-old (D and J), 6-mo-old (E and K), and 9-mo-old cheeses (F and M). Panel FFC2-USU: replicate samples of 2-wk-old (lane A and G), 6-wk-old (B and $\mathrm{H}), 3$-mo-old ( $\mathrm{C}$ and $\mathrm{I}$ ), and 6-mo-old cheeses ( $\mathrm{D}$ and $\mathrm{J}$ ). Lane $\mathrm{E}$ contains products from 9-mo-old replicate 1 cheese, and lane $\mathrm{F}$ is the positive control and standard. Panel FFC2-UW: replicate samples of 2-wk-old (lanes A and F), 3-mo-old (B and G), 6-mo-old (C and $\mathrm{H})$, and 9-mo-old cheeses (D and I). Lane E shows the positive control and standard. Panel FFC2-CPSU: replicate samples of 2-wk-old (lanes $\mathrm{A}$ and $\mathrm{G}$ ), 6-wk-old (B and $\mathrm{H}$ ), 3-mo-old ( $\mathrm{C}$ and $\mathrm{I}$ ), 6-mo-old ( $\mathrm{D}$ and $\mathrm{J}$ ), and 9-mo-old cheeses (E and $\mathrm{K}$ ). Lane $\mathrm{F}$ shows the positive control and standard. Numbers 7 and 10 to 24 correspond to DGGE fragments collected from these gels whose nucleotide sequences indicated that they were derived from bands 8 (Lactobacillus curvatus); 10 (Streptococcus macedonicus/Streptococcus equinus); 11 (Streptococcus thermophilus), 12 (Bacillus coagulans), 13 (Meiothermus silvanus); 14 (Lactobacillus helveticus); 15 (Acremonium strictum); 16, 17, and 24 (Bacillus licheniformis); 18 and 19 (Bacillus cereus/Bacillus thuringiensis); 20 (Staphylococcus epidermidis); 21 (Enterococcus faecium); 22 (Enterococcus gallinarum); and 23 (Escherichia coli).

linarum was also detected in 3- and 6-mo-old FFC2 cheese made at CPSU and in 6-mo-old FFC1 (Table 3). Nonetheless, because both species were only detected after sample enrichment via $45^{\circ} \mathrm{C}$ incubation, their original numbers in cheese samples were likely very low.

A variety of Bacillus species were intermittently detected in most cheeses after incubating cheese extract on nonselective agar (MRS) at 30 or $45^{\circ} \mathrm{C}$ (Table 3 ). Because these spore-forming, obligately aerobic bacteria were only recovered after incubation of cheese extracts on nonselective medium at temperatures considerably higher than the ripening temperature (i.e., 30 or $45^{\circ} \mathrm{C}$, but not $10^{\circ} \mathrm{C}$ ), their outgrowth is more likely an indication of dormant spores, rather than vegetative cells, in the Cheddar cheeses made for this study.
Finally, cheese extracts incubated at $45^{\circ} \mathrm{C}$ also yielded unexpected microorganisms, including Meiothermus silvanus (Figure 3, band 13), E. coli (Figure 3, band 23), and a fungus Acremonium strictum (Figure 3, band 15) (Table 3). Similar to staphylococci, the sporadic presence of E. coli was probably due to human cross-contamination during cheese processing or sample handling. The origin of $M$. silvanus, a gram-negative aerobe, and A. strictum are unknown, but their sporadic presence indicates that neither is likely to play an important role in cheese flavor development.

Overall, results from this study indicate that fat reduction altered bacterial population dynamics in Cheddar cheese in a manner that largely involved fluctuations in numbers of the same predominant species. 
Thus, populations of nonstarter bacteria were much lower in full-fat compared with low-fat cheeses made at all 3 sites, but $L b$. curvatus was the predominant NSLAB species in all cheeses at all sites. Similarly, starter viability declined at a more rapid rate during ripening in full-fat compared with 50\% reduced-fat and low-fat cheeses, but viable starter was still detected in most samples even after 9 mo of ripening. Drake et al. (2010) previously described the sensory properties of FFC and LFC made for this study at USU, and found that they contained the same types of key odorants, but large differences in their respective concentrations. After 9 mo of aging, for example, LFC had higher bitter taste intensity and contained higher concentrations of furanones, phenylethanal, 1-octen-3-one, and FFA compared with FFC of the same age. Additionally, 9-mo-old LFC and RFC had burnt/rosy flavors that were not detected in FFC (Drake et al. 2010).

Flavor development in Cheddar cheese is the result of dynamic interaction between the bacteria and enzymes present in the curd, cheese composition (e.g., pH, moisture, and salt contents), and the manufacturing and ripening conditions used. As was discussed in detail by Drake et al. (2010), use of highly controlled manufacture and ripening protocols for the cheeses made in this study helped reduce the effect of this parameter on flavor differences. That study also addressed the role of cheese composition on flavor perception, and concluded that it likely affected flavor thresholds of important volatiles and, as a consequence, influenced LFC flavor (Drake et al., 2010). Nonetheless, those authors also noted that broad differences between the respective concentrations of key volatiles in 9-mo-old FFC and LFC provided strong evidence that differences existed in the ripening biochemistry of these cheeses.

Based on those observations and our findings, we suggest that the differences in volatile concentrations across LFC, RFC, and FFC that were recorded by Drake and coworkers (2010) were largely a consequence of the interplay between cheese composition (i.e., microenvironment) and microbial population dynamics. For example, the large difference between cheese moisture content of LFC and FFC, and the concomitant difference in S/M (Table 1), would at least partly explain the greater persistence of starter bacteria and more rapid emergence of NSLAB in LFC (Mistry 1995; Nauth and Ruffie, 1995). It is our hypothesis that greater metabolic activity from starter and NSLAB, whose populations were considerably higher in LFC than FFC after 3 mo of aging (Table 2), within the microenvironment of LFC ultimately give rise to the atypical flavors that characterized this cheese (Drake et al., 2010). If this hypothesis is correct, efforts to develop effective starter systems for low-fat cheeses may require identification of both starter and adjunct strains whose physiology in the LFC microenvironment mimics that of conventional strains in FFC, and also help control emergence of wild NSLAB. This formidable task will in turn require more specific knowledge of how the cheese physicochemical environment affects starter and adjunct culture cell physiology.

\section{CONCLUSIONS}

This study explored consequences of fat removal in Cheddar cheese on population dynamics of starter and NSLAB over 9 mo of ripening. We found that fat reduction was correlated with changes in populations of different bacteria, but it did not appear to alter the predominant types of bacteria in the cheese. These observations are probably not due to changes in fat reduction alone, but rather to more wholesale changes to the cheese microenvironment (e.g., acid and S/M contents, redox, and water activity). Combined, these factors may have a pronounced effect on population dynamics of both starter and nonstarter bacteria. In this study, Lb. curvatus was the predominant NSLAB species in all cheeses from all manufacturing sites, despite substantial differences in $\mathrm{S} / \mathrm{M}$ contents and $\mathrm{pH}$ among cheeses. Other species of bacteria were sporadically detected within and between manufacturing sites, but their presence was not correlated with changes in cheese fat content. With respect to flavor development, the observed differences in bacterial population dynamics, even if they only involved changes in numbers of the same species, could be expected to alter the flavor attributes of Cheddar cheese. This hypothesis is supported by the results of Drake et al. (2010), who found that FFC and LFC made for this study at USU contained the same types of key odorants, but large differences in their respective concentrations. Thus, results from this study support the hypothesis that microbial population dynamics are altered by perturbations in the cheese microenvironment, and this phenomenon plays a significant role in atypical flavor development of low- or nonfat cheese.

\section{ACKNOWLEDGMENTS}

The authors thank Stephen Larsen (Western Dairy Center, Logan, UT), and John Jaeggi, Bilal Dosti, Gina Mode, and Kristen Houck (all from the Center for Dairy Research, Madison, WI) for technical assistance on the project. This research was supported by Dairy Management Inc. (Rosemont, IL) through the Western Dairy Center (Logan, UT), the California Dairy Foods Research Center (San Luis Obispo), and the Wisconsin Center for Dairy Research (Madison), and by the Utah 
Agricultural Experiment Station (UAES; Logan). This communication is approved as UAES Journal Paper Number 8476.

\section{REFERENCES}

Ardö, Y. 2006. Flavour formation by amino acid catabolism. Biotechnol. Adv. 24:238-242.

Beresford, T. P., N. A. Fitzsimons, N. L. Brennan, and T. M. Cogan. 2001. Recent advances in cheese microbiology. Int. Dairy J. 11:259-274.

Broadbent, J. R., C. Brotherson, C. J. Oberg, and M. E. Johnson 2002. Cheese micro-ecology and the influence of adjunct/wash techniques. Aust. J. Dairy Technol. 57:137-142.

Broadbent, J. R., K. Houck, M. E. Johnson, and C. J. Oberg. 2003. Influence of adjunct use and cheese microenvironment on nonstarter lactic acid bacteria populations in Cheddar-type cheese. J. Dairy Sci. 86:2773-2782.

Broadbent, J. R., and J. L. Steele. 2007. Biochemistry of cheese flavor development: Insight from genomic studies of lactic acid bacteria. Pages 177-192 in Flavor of Dairy Products. K. R. Cadwallader, M. A. Drake, and R. J. McGorrin, ed. Amer. Chem. Soc., Washington, DC.

Broome, M. C., D. A. Krause, and M. W. Hickey. 1990. The isolation and characterization of lactobacilli from Cheddar cheese. Aust. J. Dairy Technol. 45:60-66.

Clarridge, J. E. III. 2004. Impact of $16 \mathrm{~S}$ rRNA gene sequence analysis for identification of bacteria on clinical microbiology and infectious diseases. Clin. Microbiol. Rev. 17:840-862.

Cocolin, L., N. Innocente, M. Biasutti, and G. Comi. 2004. The late blowing in cheese: A new molecular approach based on PCR and DGGE to study the microbial ecology of the alteration process. Int. J. Food Microbiol. 90:83-91.

Cogan, T. M., T. P. Beresford, J. Steele, J. Broadbent, N. P. Shah, and Z. Ustunol. 2007. Advances in starter cultures and cultured foods. J. Dairy Sci. 90:4005-4021.

Crow, V., B. Curry, and M. Hayes. 2001. The ecology of non-starter lactic acid bacteria (NSLAB) and their use as adjuncts in New Zealand Cheddar. Int. Dairy J. 11:275-283.

Don, R. H., P. T. Cox, B. J. Wainwright, K. Baker, and J. S. Mattick. 1991. 'Touchdown' PCR to circumvent spurious priming during gene amplification. Nucleic Acids Res. 19:4008.

Drake, M. A. 2007. Defining cheese flavour. Pages 370-395 in Improving the Flavour of Cheese. B. C. Weimer, ed. CRC Press, New York, NY.

Drake, M. A., R. E. Miracle, and D. J. McMahon. 2010. Impact of fat reduction on flavor and flavor chemistry of Cheddar cheeses. J. Dairy Sci. 93:5069-5081.

Etokebe, G. E., and A. Spurkland. 2000. Method for avoiding PCRinhibiting contaminants when eluting DNA from polyacrylamide gels. Biotechniques 29:694-696.

Fenelon, M. A., P. O'Connor, and T. P. Guinee. 2000. The effect of fat content on the microbiology and proteolysis of Cheddar cheese during ripening. J. Dairy Sci. 83:2173-2183.

Fitzsimons, N. A., T. M. Cogan, S. Condon, and T. Beresford. 1999. Phenotypic and genotypic characterization of non-starter lactic acid bacteria in mature Cheddar cheese. Appl. Environ. Microbiol. 65:3418-3426.

Fox, P. F., J. Law, P. L. H. McSweeney, and J. Wallace. 1993. Biochemistry of cheese ripening. Pages 389-438 in Cheese: Chemistry, Physics and Microbiology. Vol. 1. 2nd ed. P. F. Fox, ed. Chapman and Hall, London, UK.

Fox, P. F., and J. M. Wallace. 1997. Formation of flavor compounds in cheese. Adv. Appl. Microbiol. 45:17-85.

Fryer, T. F. 1969. Microflora of Cheddar cheese and its influence on cheese flavour. Dairy Sci. Abstr. 31:471-490.

Hardie, J. M. 1986. Genus Streptococcus. Pages 1043-1071 in Bergey's Manual of Systematic Bacteriology. Vol. 2. 9th ed. P. H. A Sneath, N. S. Mair, M. E. Sharpe, and J. G. Holt, ed. Williams and Wilkins, Baltimore, MD.

Kloos, W. E., and K. H. Schleifer. 1986. IV. Genus Staphylococcus. Pages 1013-1035 in Bergey's Manual of Systematic Bacteriology. Vol. 2. 9th ed. P. H. A. Sneath, N. S. Mair, M. E. Sharpe, and J G. Holt, ed. Williams and Wilkins, Baltimore, MD.

Marilley, L., and M. G. Casey. 2004. Flavours of cheese products: Metabolic pathways, analytical tools and identification of producing strains. Int. J. Food Microbiol. 90:139-159.

Milo, C., and G. A. Reineccius. 1997. Identification and quantification of potent odorants in regular-fat and low-fat mild Cheddar cheese. J. Agric. Food Chem. 45:3590-3594.

Mistry, V. V. 1995. Improving the sensory characteristics of reducedfat cheese. Pages 371-382 in Chemistry of Structure-Function Relationships in Cheese. E. L. Malin and M. H. Tunick, ed. Plenum Press, New York, NY.

Muyzer, G., E. C. De Waal, and A. G. Uitterlinden. 1993. Profiling of complex microbial populations by denaturing gradient gel electrophoresis analysis of polymerase chain reaction-amplified genes coding for 16S rRNA. Appl. Environ. Microbiol. 59:695-700.

Nauth, K. R., and D. Ruffie. 1995. Microbiology and biochemistry of reduced-fat cheese. Pages 345-358 in Chemistry of StructureFunction Relationships in Cheese. E. L. Malin and M. H. Tunick, ed. Plenum Press, New York, NY.

Ogier, J.-C., and P. Serror. 2008. Safety assessment of dairy microorganisms: The Enterococcus genus. Int. J. Food Microbiol. 126:291-301.

Peterson, S. D., and R. T. Marshall. 1990. Nonstarter lactobacilli in Cheddar cheese: A review. J. Dairy Sci. 73:1395-1410.

Rogers, N. R., M. A. Drake, C. R. Daubert, D. J. McMahon, T. K Bletsch, and E. A. Foegeding. 2009. The effect of aging on low-fat, reduced-fat, and full-fat Cheddar cheese texture. J. Dairy Sci 92:4756-4772.

Sambrook, J., E. F. Fritsch, and T. Maniatis. 1989. Molecular Cloning: A Laboratory Manual. 2nd ed. Cold Spring Harbor Laboratory, Cold Spring Harbor, New York.

Smit, G., B. A. Smit, and W. J. Engels. 2005. Flavour formation by lactic acid bacteria and biochemical flavour profiling of cheese products. FEMS Microbiol. Rev. 29:591-610.

Swearingen, P. A., D. J. O'Sullivan, and J. J. Warthesen. 2001. Isolation, characterization, and influence of native nonstarter lactic acid bacteria on Cheddar cheese quality. J. Dairy Sci. 84:50-59.

Van Slyke, L. L., and W. V. Price. 1979. Cheese. Ridgeview Publ. Co., Atascadero, CA. 